\title{
What Is the Future of Impedance Planimetry in Gastroenterology?
}

\author{
Hans Gregersen ${ }^{1,2 *}$ and Kar Man Lo ${ }^{3}$ \\ ${ }^{\text {I}}$ GIOME, Department of Surgery, The Chinese University of Hong Kong; Shatin, Hong Kong; ${ }^{2}$ California Medical Innovations Institute, San \\ Diego, California, USA; and ${ }^{3}$ GIOME Doublecove, Wu Kai Sha, New Territories, Hong Kong
}

The gastrointestinal $(\mathrm{Gl})$ tract is efficient in transporting ingested material to the site of delivery in healthy subjects. A fine balance exists between peristaltic forces, the mixing and delivery of the contents, and sensory signaling. This fine balance is easily disturbed by diseases. It is mandatory to understand the pathophysiology to enhance our understanding of GI disorders. The inaccessibility and complex nervous innervation, geometry and mechanical function of the Gl tract make mechanosensory evaluation difficult. Impedance planimetry is a distension technology that assesses luminal geometry, mechanical properties including muscle dynamics, and processing of nociceptive signals from the Gl tract. Since standardized models do not exist for Gl muscle function in vivo, models, concepts, and terminology must be borrowed from other medical fields such as cardiac mechanophysiology. The review highlights the impedance planimetric technology, muscle dynamics assessment, and 3 applied technologies of impedance planimetry. These technologies are the multimodal probes that assesses sensory function, the functional luminal imaging probe that dynamically measures the geometry of the lumen it distends, and Fecobionics that is a simulated feces providing high-resolution measurements during defecation. The advanced muscle analysis and 3 applied technologies can enhance the quality of future interdisciplinary research for gaining more knowledge about mechanical function, sensory-motor disorders, and symptoms. This is a step in the direction of individualized treatment for GI disorders based on diagnostic subtyping. There seems to be no better alternatives to impedance planimetry, but only the functional luminal imaging probe is currently commercially available. Wider use depends on commercialization of the multimodal probe and Fecobionics.

(J Neurogastroenterol Motil 2018;24:166-181)

\section{Key Words}

Electric impedance; Gastrointestinal tracts; Luminal; Medical devices; Muscle Strength

\section{Introduction}

Proper function of the gastrointestinal (GI) tract requires that its mechanical and mechanosensory operations are normal. However, normal motor behavior in the GI tract includes a good deal of variation because, as a self-regulated mechanical device, it monitors its own functions and modifies them continuously. Examination of the GI tract encompasses both mechanical events in relation to the physical conditions in the muscular wall and biochemical conditions in relation to the milieu of the lumen. Neural mechanoreceptors in the wall and neural chemoreceptors in the mucosal epithelium receive a variety of kinds of inputs continuously and respond in ways that modify the mechanical functions. ${ }^{1-6}$ The GI tract is affected by a variety of diseases. ${ }^{7}$ Disturbed mechanical function is sometimes the most conspicuous aspect of the disease. For example for

Received: January 12, 2018 Revised: None Accepted: February 9, 2018

(c) This is an Open Access article distributed under the terms of the Creative Commons Attribution Non-Commercial License (http://creativecommons. org/licenses/by-nc/4.0) which permits unrestricted non-commercial use, distribution, and reproduction in any medium, provided the original work is properly cited.

*Correspondence: Hans Gregersen, MD, PhD GIOME, Department of Surgery, 4/F, Clinical Sciences Building, Prince of Wales Hospital, Shatin, Hong Kong Tel: +852-6921-8406, Fax: +852-2637-7974, E-mail: hag@giome.org 
the esophagus, this seems natural considering that the esophagus primarily serves the mechanical function of transporting ingested food and fluids to the stomach, or venting air. Esophageal achalasia is perhaps the best known esophageal disease characterized by disturbed mechanical function. This kind of disease is commonly spoken of as the motor disorders of the GI tract.

A fine balance exists between the peristaltic forces generated in the GI tract, the mixing and delivery of the intestinal contents, and sensory signaling. This fine balance is easily disturbed by diseases. Since standardized models do not exist for GI muscle function, models, concepts and terminology must be borrowed from other medical fields such as cardiac mechanophysiology. It is mandatory to understand the complex pathophysiology of the GI tract to enhance our understanding of GI disorders. The inaccessibility, and complex nervous innervation, geometric, and mechanical function of the GI tract makes mechanosensory evaluation difficult. Impedance planimetry is a distension technology that was developed during recent decades. ${ }^{6,8-10}$ Impedance planimetry and its applied technologies have made it possible to get insight into luminal geometry, mechanical properties including muscle dynamics, and processing of nociceptive signals from the GI tract. ${ }^{1,6,8-13}$

The current review highlights the impedance planimetric technology, muscle dynamics assessment, and 3 applied technologies of impedance planimetry. These technologies are the multimodal probes that assesses sensory function, the functional luminal imaging probe (FLIP) that measures the geometry of the lumen it distends, and Fecobionics that is a simulated feces providing highresolution measurements during defecation. These technologies as outlined in the review gives the possibility for researchers in the future to enhance the quality of interdisciplinary research and to gain more knowledge about motor disorders, sensory symptoms and treatment options.

\section{Gastrointestinal Distension Studies and Impedance Planimetric Technology}

In the mid-1980s, there was an increasing recognition that provocative tests were useful in studies of GI function. Such tests would not only measure the background activity in the gut such as the pressure patterns but would also test how the organ reacted to a specific stimulus such as a mechanical stimulus. Several ways exist to stimulate the GI tract mechanically. Simple and physiological methods for distension of the gut such as ingestion of welldefined meals may be useful. ${ }^{14}$ However, balloon or bag distension is used more frequently as the mechanical stimulation intensity can be controlled. For intraluminal bag distension technologies the stimulus will provoke mechanosensitive receptors in the organ wall and thereby test the mechanosensory system. In many studies distensions were based on pressure-volume measurements using latex balloons or the barostat. ${ }^{15-18}$ However, there were concerns related to the lack of data on the geometry of the distending balloon or bag. Consequently, the stimulation field and the influence of muscle contractions and relaxations would not be known, as well as lack of reproducibility due to strain softening, and errors in computation of wall tension would be concerns with those technologies. ${ }^{6,8,19,20}$

Impedance planimetry was developed in the late 1980s as an alternative technology for distension of the GI tract. The rationale for the development was many-fold. Most importantly a better tool for assessment of distensibility and for assessment of the mechanical parameters closely associated with mechanoreceptor activation was warranted. Impedance planimetry was less biased by the limitations of the other technologies described above. It was recognized that pressure-diameter or pressure-cross-sectional area (P-CSA) measurements provided a means of assessing the dynamic muscle functional properties as well as passive wall properties at a single location in the GI tract. ${ }^{6,8,21}$

The development of impedance planimetry was inspired from other medical fields. Studies with impedance technology using probes with or without bags had been done in urology in the 1970s based on a theoretical study published by Harris et $\mathrm{al}^{22-24}$ in 1971 . Impedance measurements were also widely used for determination of the volume of the left ventricles of the heart. ${ }^{25}$ However, these impedance technologies were not directly applicable for GI distension studies. Modifications were needed in terms of dimensions, electronics, signal processing and distension protocols. The first GI studies using a four-electrode principle were published in $1988 .^{26}$ The term "Impedance planimetry" first appeared in a publication from 1991 and have been used since then. ${ }^{27}$ The abovementioned developments of impedance technology in urology and the cardiac fields also paved the road for the intraluminal impedance catheters often used in evaluations of gastroesophageal reflux and esophageal clearance. $^{28}$

Impedance planimetry measures P-CSA relations inside the distending bag, ie, the luminal dimension will be measured at the distension site. The principle of CSA measurement is rather simple and based on Ohm's law. Four electrodes are placed on the catheter inside a bag filled with conducting fluid. Two outer excitation electrodes generates a constant alternating current (typically $100 \mathrm{~mA}$ at $5 \mathrm{kHz}$ ). A pair of detection electrodes located between the excitation electrodes measures the voltage difference between them (Fig. 
1). The voltage difference is proportional to the CSA multiplied by a calibration constant. ${ }^{8,26,27,29}$ Sources of error are well described and can be handled with ease. ${ }^{8,27,29}$ The luminal diameter or the inner wall circumference can be computed from the CSA measurement which can be used for computation of mechanical parameters such as tension (the product of the pressure and the radius) and strain (a measure of deformation).

Impedance planimetry was initially used in animal models. These span from physiological studies of distensibility in various parts of the GI tract ${ }^{26,31}$ to studies of disease models such as the obstructed opossum esophagus. ${ }^{32-34}$ Numerous studies followed in humans. Physiology studies in humans primarily focused on:

- Measurement of real-time tension in the esophagus ${ }^{35}$

- Strain as the most reliable stimulation parameter for the sensory response to distension ${ }^{13,36,37}$

- Demonstration of intestinal tone and its dependency on the interdigestive phases ${ }^{38,39}$

- Variation in distensibility along the esophagus ${ }^{40,41}$

- Esophagogastric junction (EGJ) and anal sphincter measurements. $^{41,42}$

- GI muscle function evaluation (see below)

- Mechanosensation including central integration, sensitization mechanisms, and strain-dependency of mechanoreceptor-medicated responses ${ }^{43-53}$ (see the section on the multimodal probe below)

- Preconditioning behavior ${ }^{37,43,54}$

In addition to the numerous multimodal studies listed later in this paper, clinical studies using impedance planimetry focused on the following areas and diseases:

- Hyperalgesia in patients with non-cardiac chest pain $(\mathrm{NCCP})^{55}$

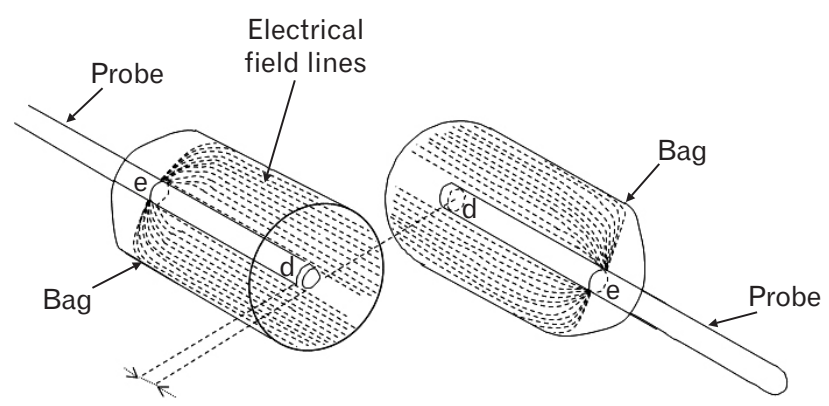

Figure 1. Schematic of the impedance planimetry probe. [d] and [e] indicates the detection and excitation electrodes.
- GI tract stiffening in systemic sclerosis ${ }^{54,56-58}$

- Hypersensitivity in IBS and its dependency on pain processing in the central nervous system ${ }^{59}$

- Hypersensitivity and increased tone of the sigmoid in patients with active ulcerative colitis ${ }^{60}$

- Rectal tone changes in patients with spinal cord injury ${ }^{61}$

GI muscle properties are important because the GI tract primarily serves a mechanical function by mixing and transporting the contents to the site of delivery. The muscle delivers the forces that moves the intraluminal matter. Hence, better assessment of GI muscle dynamics is warranted. Impedance planimetry and its applied technologies offer such an assessment which was inspired from cardiovascular studies.

\section{Advanced In Vivo Muscle Function Studies: From Cardiology to Gastroenterology}

Evaluation of GI muscle function has primarily been based on manometry with analysis of parameters such as contraction amplitude, number of contractions, peristaltic velocity, and patterns of contractions. Impedance planimetric distension data allow much more detailed and structured analysis of contractility. A key feature is that impedance planimetry measures pressure as well as geometric data. Consequently tension and strain can be calculated. These mechanical measures are important for several reasons as outlined below. In GI physiology we can learn from the development of parameters and concepts in cardiac mechanics as listed in Table.

Like the GI tract, the heart primarily serves mechanical functions. The study of muscle and whole organ mechanics in the cardiac field developed way before that in gastroenterology where such studies and concepts yet are in the infancy. It is useful to consider cardiac mechanics and models of the active and passive mechanical behavior for obtaining a better understanding of GI function and remodeling in GI disorders. The table refers to the left side of the heart, ie, the left ventricle and injection of blood into the aorta. The description and concepts are quite basic from a cardiovascular physiology point of view. The interested reader can first seek information in cardiac physiology books. ${ }^{19}$ The scientific literature on the topic is abundant and offers further in-depth readings. Obviously, the cardiac models and equations may need modifications to be applied to the GI tract due to differences in anatomy and geometry, but it is evident that there are many similarities and that impedance planimetry offers a new way to assess GI muscle function. Using impedance planimetry, it has been possible to derive parameters such as 


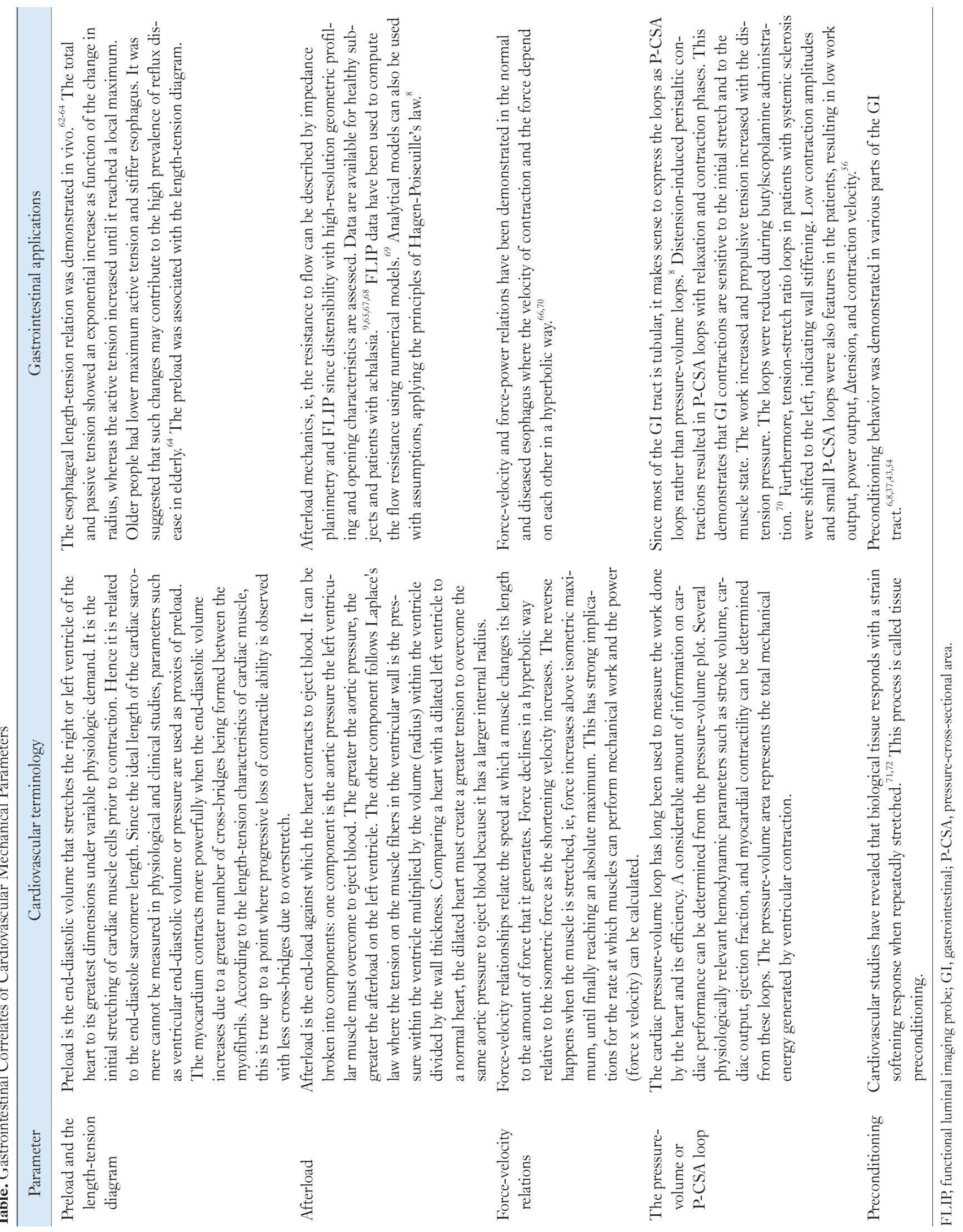


Length-tension
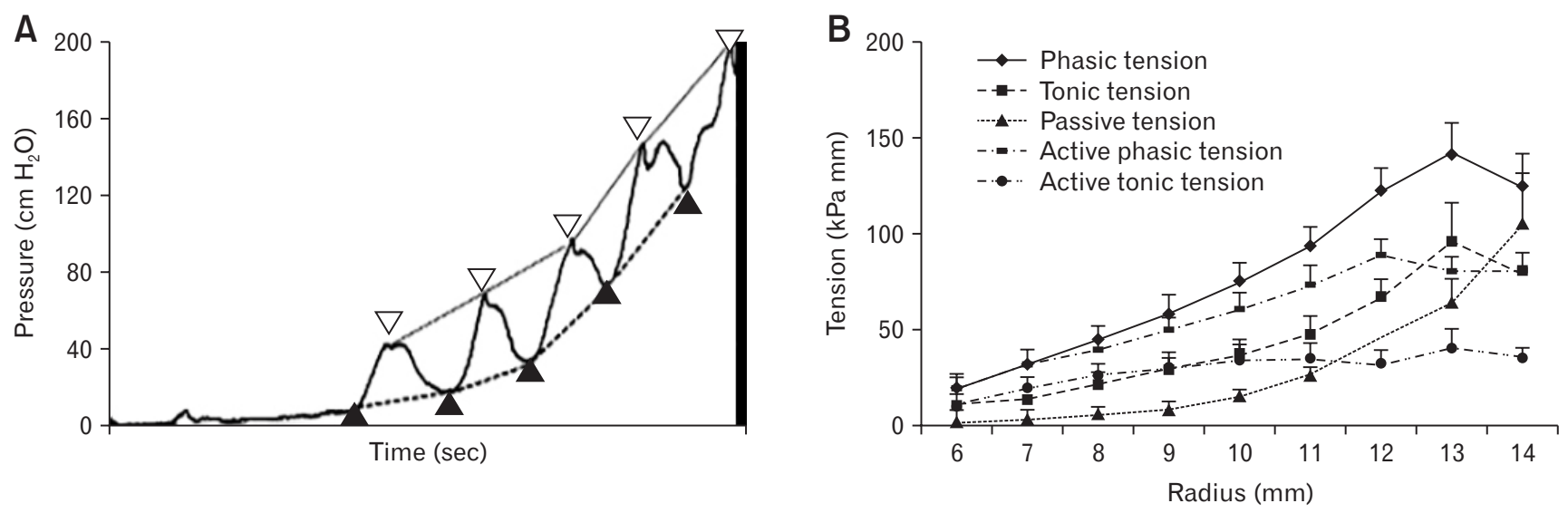

Force-velocity
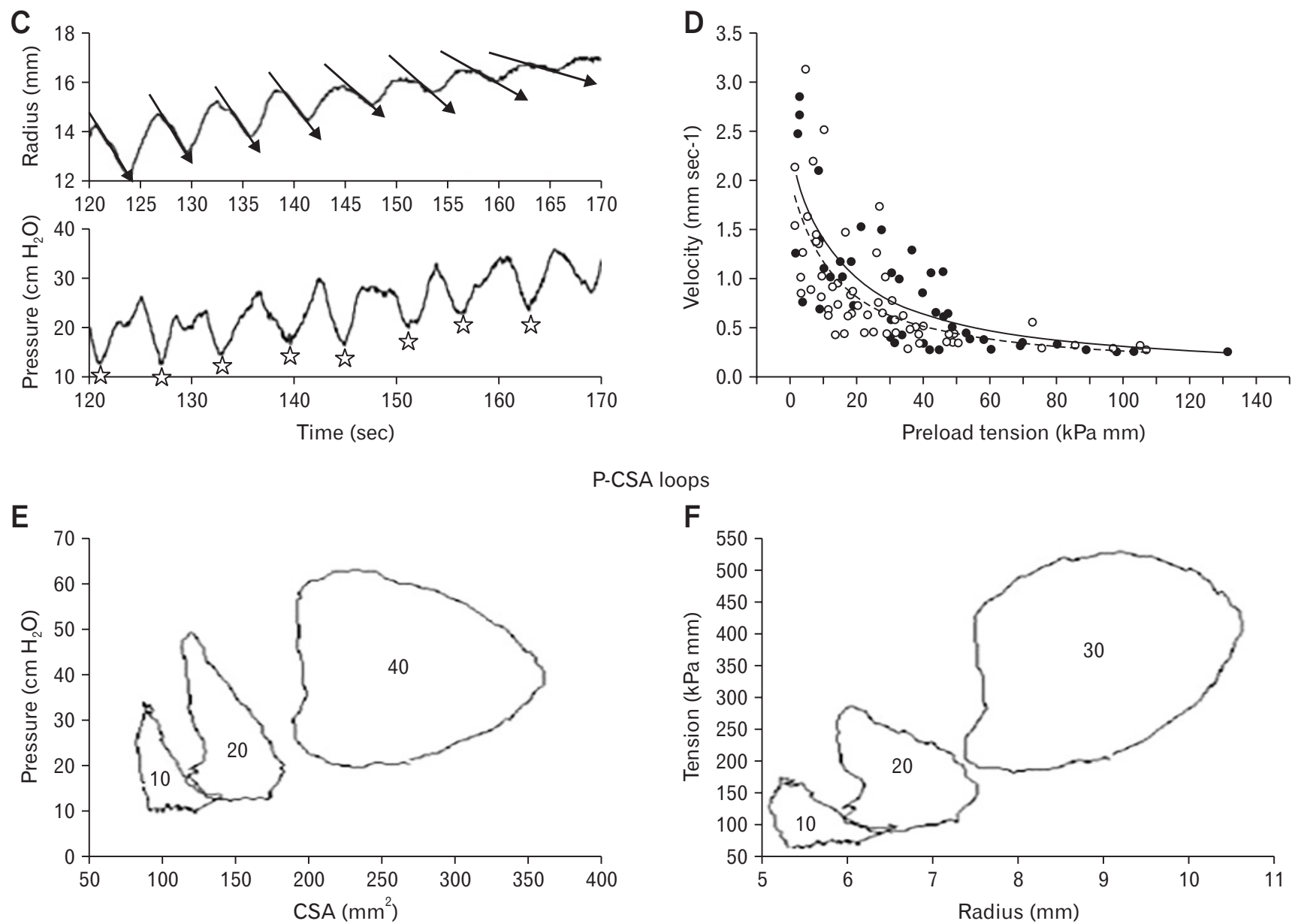

P-CSA loops

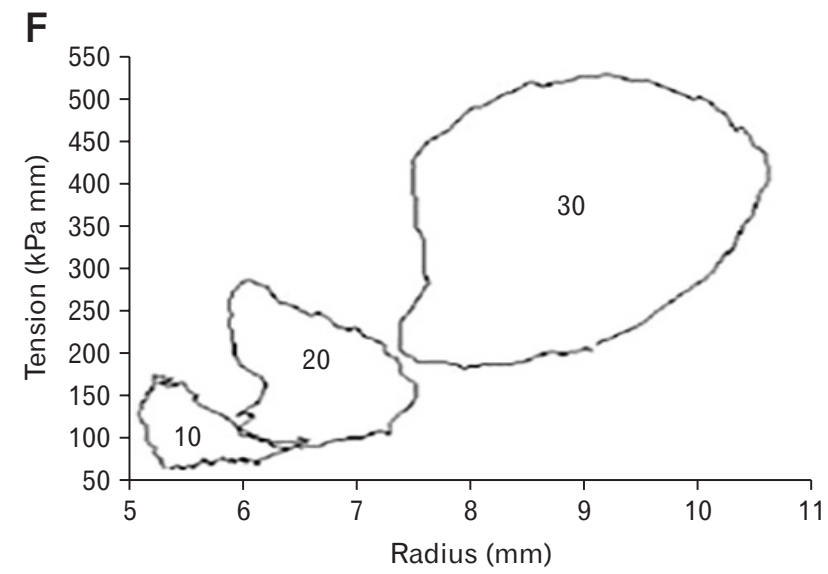

Figure 2. Illustration of different gastrointestinal (GI) muscle properties. Panel A shows the bag pressure during distension in the human esophagus and the derived length-tension diagram is shown in panel B. Panel C shown simultaneous radius and pressure measurements during a distension. The arrows show the radius change (slope) during contractions. The slope depends on the degree of distension. The data can be converted to a force-velocity diagram as shown in panel D. Each contraction will result in a pressure-cross-sectional area (P-CSA) loop. This is illustrated in panel $\mathrm{E}$ at 3 distension levels (bag pressure of 10, 20, and $40 \mathrm{cmH}_{2} \mathrm{O}$ ). The P-CSA loop can be converted to a tension-radius loop for better comparison between experiments (panel F). 
active-passive length-tension diagrams, force velocity curves, preload-afterload diagrams, and loop diagrams (Fig. 2). ${ }^{56,57,62,63}$ This opened up a completely new way of studying GI muscle properties in vivo, ${ }^{6,89,56,57,64-66}$ which will likely impact the way GI muscle function is assessed and interpreted in the future. Some clinical implications of this type of analysis have been outlined. ${ }^{6}$

\section{Specialized Impedance Planimetric Technologies and Their Applications}

Three applied technologies of impedance planimetry have been developed. The first technology was developed in the early 2000s for assessing sensory mechanisms. Due to the battery of stimulation modalities, it was named the multimodal probe. The second technology was brought forward a few years later and provided high-resolution geometric measurements, ie, geometric profiling of the distended organ. It was named the FLIP. The third technology based on impedance planimetry is in its infancy but nevertheless show great potential in future anorectal applications. Whereas the multimodal technology and FLIP measure at preselected locations such as in the anal sphincters, Fecobionics provides a variety of measurements during intestinal transport of the device.

The 3 applied technologies are described separately below.

\section{The Multimodal Probe}

\section{Background}

Visceral diseases are typically associated with unspecific symptoms such as discomfort and pain. The sensory feeling is often vague and patients find it difficult to characterize it, in contrast to the distinct localization in somatic pain. Such GI disorders are commonly encountered in clinical practice with pain as one of the most frequently presented symptoms. Manifest visceral pain originates from a variety of underlying pathologies. Pain is a complex multidimensional experience comprising sensory-discriminative, affectivemotivational and cognitive-evaluative components. ${ }^{73-75}$ Thus, gastroenterologists are challenged in treating GI pain because the underlying diseases often are difficult to diagnose correctly.

In clinical practice, the symptomatology of underlying diseases is often confounded by complaints relating to psychological, cognitive, and social aspects of the illness as well as systemic reactions such as fever affect the experienced symptoms. Furthermore, pharmacological treatment may cause undesirable adverse effects, which bias the clinical evaluation of the symptoms. Experimental pain models are designed to cover the confounding factors, which then can be turned to advantages in the assessment of basic GI func-

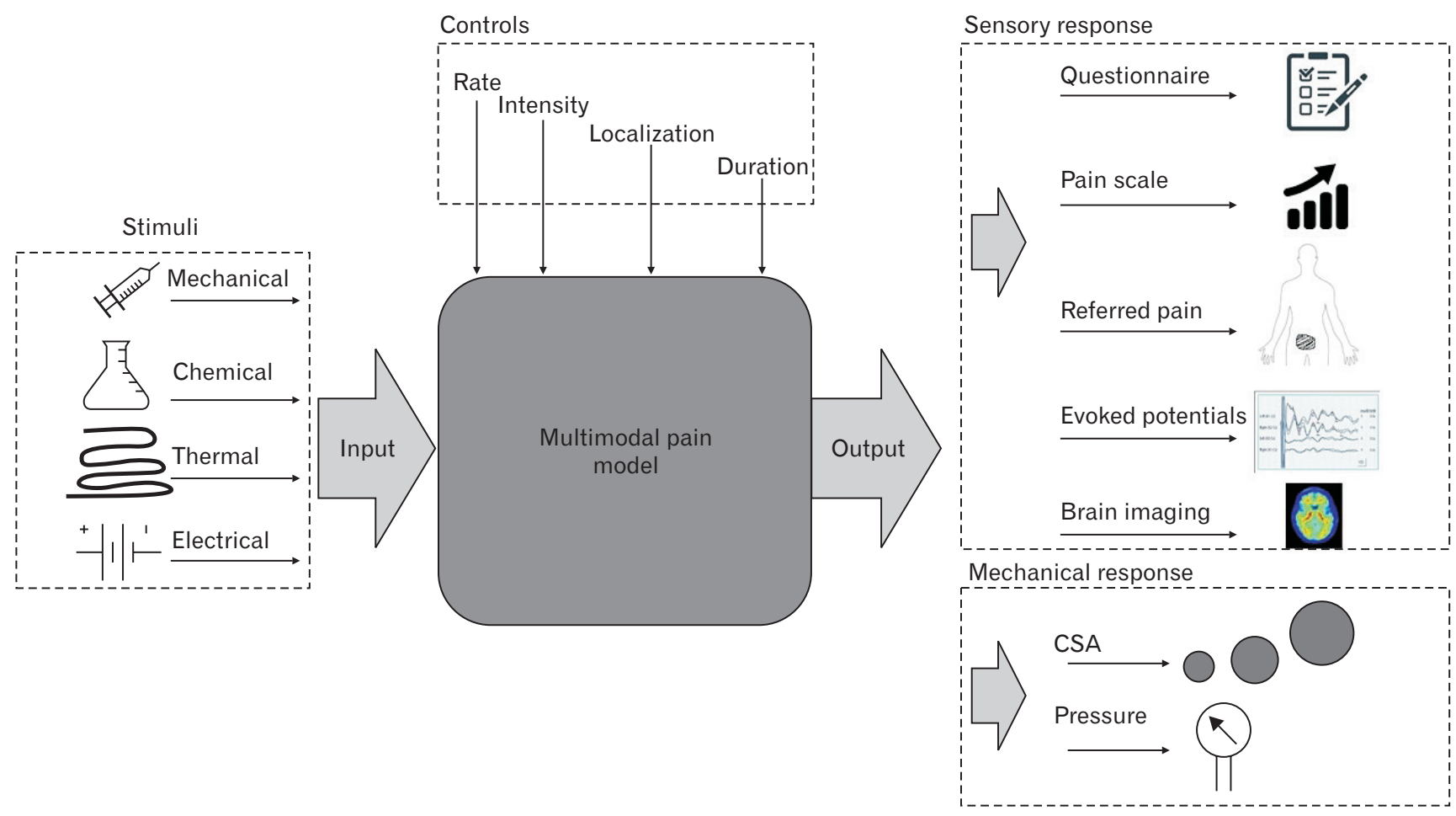

Figure 3. Schematic of stimulation and assessment modes in experimental pain models. CSA, cross-sectional area. 
tions, mechanisms of disease, and treatment efficacy. Under these controlled facilities, the investigator controls the nature, localization, intensity, frequency, and duration of the applied stimulus, and assesses the quantitative measures of the psychophysical, behavioral, or neurophysiological responses (Fig. 3). ${ }^{76}$

The ideal experimental stimulus to elicit visceral pain in man should be natural, minimally invasive, reproducible, and quantifiable. ${ }^{77}$ Preferably the pain should mimic the observations in diseased organs by evoking phenomena such as allodynia and hyperalgesia. $^{78}$ Some stimulation methods seem to fulfill these requirements, but most laboratories use their own stimulation paradigms, often without the necessary standardization. The different methods for pain stimulation of the GI tract are based on:

- Mechanical stimulation (see references above)

- Chemical stimulation ${ }^{79-95}$

- Thermal stimulation ${ }^{96-97}$

- Electrical stimulation ${ }^{98,99}$

- Ischemic stimulation ${ }^{100,101}$

Experimental pain models have the advantage that specific receptors and pathways can be selectively activated. Consequently the effect of pathophysiological conditions on such evoked responses can be studied systematically. On the other hand, one major limitation of most experimental pain models in the GI tract is that they mimic only part of the clinical pain mechanisms. This is because experimental pain is relatively short-lasting and without activation of the many peripheral and central nervous mechanisms that are typically activated during diseases. Clinical pain is a sum of many pain mechanisms, where experimental pain based on a single modality recruits only parts of these mechanisms. ${ }^{13}$ Therefore, a multimodal testing approach must be used which will increase the probability for activation of a range of relevant neural mechanisms. Especially if the stimulation is relatively long lasting and includes modalities known to evoke peripheral as well as central sensitization, the likelihood that the model will mimic clinical pain is high despite the nonharmful nature of the stimulation. In the GI tract difficulties with access to the organs and technical limitations of the currently available models have made such a multimodal stimulation approach difficult.

Treatment of pain is one of the major challenges in clinical medicine as it is often difficult to evaluate the effect of a treatment because the symptoms of the underlying diseases often confound this assessment. Human experimental pain models offer the possibility to explore the pain system under controlled settings. The models can also be used to screen the analgesic profiles of drugs targeted to treat pain. ${ }^{102}$ Thus, if the patients are individually tested with a sensory testing battery to unravel at which levels the pain system is reacting abnormally, the most appropriate treatment can theoretically be selected.

\section{Multimodal technology}

The multimodal probe consists of a catheter with an impedance planimetric bag for distension (mechanical stimulation). The probe also contains side holes for injection of chemicals above the bag (chemical stimulation), and silver-chloride stimulation electrodes on the catheter or bag for electrical stimulation. Short and long pulsed electrical stimulation signals can be delivered across the electrodes giving current to a maximum of $80 \mathrm{~mA}$ or until the pain detection threshold is detected. Furthermore, the water inside the bag can be heated or cooled by recirculating the fluid (thermal stimulation) using a reservoir and pump system, or a thermistor element. Furthermore, the multimodal probe will record the CSA and multiple pressures as well as the study subject report symptoms, the pain level on a visual analog scale, and referred pain areas. Objective sensory information can be assessed by recording evoked potentials from the brain or by imaging technology.

\section{Multimodal studies}

It is out of the scope of this paper to make a complete review of the numerous publications using the multimodal approach. The reader is referred to other literature for a comprehensive review of the studies where the multimodal model have been used. ${ }^{1,6,11,12,103}$ In brief, it has been used in different parts of the GI tract to assess the sensory response of controlled stimulations in healthy subjects and in various patient groups. In healthy subjects, sensory responses and mechanisms related to gender, age, and other factors were studies in the esophagus, ${ }^{44,48-52,79,82,83}$ small intestine, ${ }^{37,104,105,106}$ and large intestine including the rectum. ${ }^{107,108}$ Clinical studies have been published on gastroesophageal reflux disease (GERD), non-cardiac (functional) chest pain, and Barrett's esophagus, ${ }^{45,46,53,79,109-116}$ and on diabetic gut function. ${ }^{117,118}$ In addition, several pharmacological studies were published, in particular related to testing of opioids. $^{12,102,106,119,120}$

\section{The future for the multimodal technology}

It is evident that multimodal assessment offers deep insight into sensory mechanisms due to its multiple controlled stimulation modes and assessment of sensory-motor data. This allows for subtyping of patients which is important for individualized treatment. 
At present, no other technology provides such kind of measurements. A prominent example is the capability of the technique to differentiate pain mechanisms in patients with GERD, non-erosive reflux disease (NERD), and NCCP, ie, NCCP, NERD, and GERD patients are normo-, hyper-, and hypo-mechanosensitive, respectively, as well as the differences in acid and thermal sensitivity. ${ }^{45,46,53,116}$ The potential for subtyping patients with IBS and functional dyspepsia is obvious and needs to be explored further. Multimodal technology will facilitate the design of subsequent clinical (phase III) studies. Hence, a substitution of the current "trial and error design" with a more mechanism based approach will reduce the economic and human burden in the development of new drugs targeted against GI pain. Furthermore, experimental pain studies would be valuable in phase I studies of potential pain killers, where screening may provide knowledge about analgesic properties and interference with evoked pain mechanisms before the drug enters large clinical studies. This may improve design of phase II and III studies and be directed against patients assumed mainly to suffer from the type of pain where the drug has potential effects. However, the multimodal technology is not yet commercialized and therefore has not gained widespread use. Most publications come from a few specialized research groups. Commercialization is needed for clinical breakthrough.

Future studies should use the multimodal technology in experimental pain stimulation of different patient groups to gain more information about the pain system. Recordings of evoked potentials and non-invasive neuroimaging combined with multimodal technology can be used to explore the mechanisms behind visceral pain transduction, processing and perception in patients with functional GI disorders. ${ }^{121,122}$ Together with pharmacological studies, such interventions could lead to a mechanism based treatment approach in patients with visceral pain.

\section{Functional Luminal Imaging Probe}

\section{Background}

GI sphincters have an important role in the control of flow of liquids and solids being transported in the GI tract. Inadequate function of sphincters is the basis of many GI diseases. Perhaps the best examples are the obstructions created by the non-relaxing lower esophageal sphincter (LES) in achalasia and the loose LES associated with GERD. Traditionally, sphincters were studied by pull-through and stationary manometric techniques, by the Dent sleeve and, more recently using high-resolution manometry (HRM). ${ }^{123-125}$ Manometry and the Dent sleeve proved useful for showing transient lower sphincter relaxations, and impaired LES relaxation in patients with achalasia. HRM has gained widespread use in physiology and clinical laboratories. However, valves do not necessarily have to squeeze tight to be competent. Therefore, manometric studies only provide part of the assessment. In fact, manometric data show poor correlation with the strength and competence of sphincters. ${ }^{126,127}$ It has long been thought that measurement of sphincter function through resistance to distension is a better approach, now more commonly known as distensibility testing. Measuring the amount of opening or the opening pattern as cross sectional geometry of a valvular region will provide better diagnostic information. ${ }^{128}$

Several attempts were made to measure the geometry of sphincters for assessment of distensibility. Some successful measurements by means of conventional impedance planimetry were made in the LES and the anal sphincter though there were problems placing the rather short bag in the sphincter. ${ }^{42,129}$ Groups led by Shaker, Mittal and Pandolfino independently developed other distension devices. However, none of these have become common practice due to limitations caused by use of radiation, technical difficulties, and geometry related factors. ${ }^{130-132} \mathrm{~A}$ major step forward in the development of impedance planimetry was made in 2004 and onwards with designs of probes capable of making multiple CSA measurements in rectal studies. ${ }^{133}$ This led to the early FLIP studies by McMahon and coworkers on the EGJ. ${ }^{65,127,134,135}$ As outlined below FLIP represents a good practical method to measure distensibility in sphincters and other parts of the GI tract since it easily captures the geometry of the whole sphincter region. For measurement in the GI tract, distensibility is usually defined as the relationship between the minimum CSA in the narrow region and the bag pressure.

\section{Functional lumen imaging probe technology}

The basic principle of FLIP is that of impedance planimetry, ie, measurements of the CSA inside a distending bag from electrical impedance measurements. However, FLIP has many pairs of detection electrodes and therefore can measure a longitudinal series of CSAs inside the bag. Currently the standard is 16 CSA measurements. Since the bag is much longer than the traditional impedance planimetry bags, it is easier to conduct sphincter distension without the bag dislocating to low-pressure zones adjacent to the sphincters. Furthermore, the multiple CSA measurements will ensure that the narrowest part of the sphincter can be captured during the whole distension, even if the catheter and bag slide forward or backwards a bit.

Another important development was made in the analysis and 
display of the FLIP data. Firstly, the data were presented as semi3-dimensional (3D) geometric plots since it is not easy to interpret continuous data streams from numerous channels (Fig. 4). This is the classic FLIP representation which in sphincters will show an hour-glass shape. The early studies in the rectum ${ }^{133}$ and $\mathrm{EGJ}^{134,135}$ also led to the adoption of the color contour plotting technology that was pioneered for HRM by Ray Clouse in the early 1990s. ${ }^{136,137}$ This modified plotting technology allows display of the dimensional changes during distension in colour as function of time (Fig. 4). ${ }^{10}$ Thirdly, in most studies published, the distensibility was evaluated in terms of very simple measures such as simply looking at the magnitude of the CSA or dividing the CSA with the pressure at a given point of distension. ${ }^{138-141}$ This may introduce errors. The opening pressure, the level of distension, and the actual slope of the mechanical data curves must also be taken into account. The sphincter elasticity have in some studies been evaluated in terms of the pressure-strain modulus (elastic modulus $[\mathrm{Ep}]=$ change in pressure/ change in diameter $\times$ diameter at a reference state). ${ }^{142}$ Whereas this parameter is clearly more reliable and valid than the distensibility mentioned above, more advanced mechanical parameters should be considered. ${ }^{6,8}$ While these biomechanical metrics are important, they are not always obvious to busy clinicians who are under time pressure to make rapid clinical decisions.

\section{Studies}

It is out of the scope of this paper to review the numerous publications using FLIP. The reader is referred to other literature for a comprehensive review of FLIP studies. ${ }^{10}$ In brief, FLIP has been used in different parts of the GI tract to assess the geometric and mechanical properties in healthy subjects and in various patient groups. Studies have been done in the upper esophageal sphinc- ter, ${ }^{143-145}$ esophageal body in eosinophilic esophagitis, ${ }^{146,147}$ EGJ related to achalasia, GERD, Barrett's esophagus, systemic sclerosis, and various treatments such as anti-reflux surgery and peroral endoscopic myotomy (POEM), ${ }^{146,148-159}$ pylorus $^{160}$ and anal canal related to fecal incontinence, and gender differences. ${ }^{139,142,161,162}$

\section{The future of the functional luminal imaging probe technology}

FLIP is widely available since it was commercialized almost a decade ago. Nevertheless, it is still in its infancy with many physiological, diagnostic and therapeutic aspects yet to explore. No other technology can provide the same kind of dynamic data. FLIP has revolutionized our way of studying sphincters, seems valuable in subtyping of diseases like achalasia and fecal incontinence, and for assessment of the outcome of anti-reflux surgery. There are recent indications that FLIP is better than HRM for assessment of achalasia. Quite a lot of work has accumulated on intraoperative assessment of the efficacy of POEM and Heller myotomy. The future will show if FLIP will truly improve the outcome of endoscopic and surgical procedures. Work is also ongoing in other sphincters and in non-sphincteric regions.

In the future we will hopefully see further improvements of FLIP and analysis of FLIP data. For the catheters, this may range from longer bags to more electrode pairs, better spatial resolution, and multiple pressure measurements. Concerns have been raised about analyzing distension data based on too simple parameters. ${ }^{6,8}$ The same concerns are valid for FLIP analysis. ${ }^{140,141}$ Studies have been initiated to shed light on distensibility parameters and their value as clinical endpoints. It is also to be expected that the advanced muscle analysis as outlined previously in this paper will be used in FLIP analysis. Much can be gained from the kind of analysis and
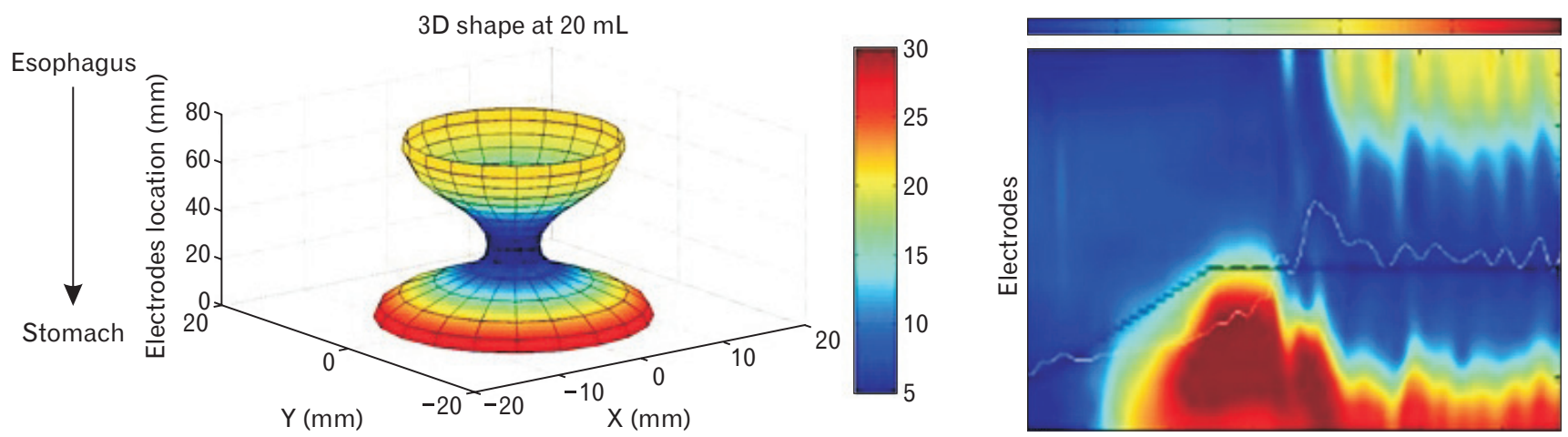

Figure 4. The typical "hour-glass" representation of functional luminal imaging probe data (top) and a color contour plot (topography) at the bottom. The color scale from blue towards red indicates increasing diameter. The white line is the bag pressure and the heavy black line represents the volume. 
FLIP is an eminent technology to provide detailed geometric data of the GI lumen.

\section{Fecobionics}

\section{Background}

Defecation is a complex physiological process through which stools are eliminated from the rectum. ${ }^{163}$ Defecatory disorders are frequent, especially in the elderly, and affect up to $25 \%$ of the population. However, defecatory disorders remain poorly recognized and treated. ${ }^{164,165}$ The lack of physiologically relevant and easy-to-use diagnostic tests for identifying the underlying mechanisms is a significant problem. The opening characteristics of the anal sphincter and relaxation of the puborectalis muscle during defecation must be described in detail which is not possible with current technology. For example, the balloon expulsion test does not assess geometry, defecography does not provide information about anorectal pressures, and HRM is not performed during defecation but is a static measurement. Considerable disagreement exists between the results of various anorectal tests and they correlate poorly with symptoms and treatment outcomes. ${ }^{164-166}$ Attempts have been made to make artificial stool for evaluation of defecation such as Fecom ${ }^{167}$ but it did not become widely available. A new technology was warranted that would fundamentally rethink the approach to anorectal functional testing.

\section{Fecobionics technology}

Fecobionics is a simulated stool, a biomechatronics device, capable of dynamic measurements of a variety of variables during passage inside the gut and during defecation. The development was based on the bionics concept (https://en.wikipedia.org/wiki/Bionics). Fecobionics imitates the defecation process and provide geometric mapping and manometric profiles in a single examination. It has the consistency and shape of normal stool. It records pressures, orientation, electrical impedances, and viscoelastic properties during defecation. It is made of a $10 \mathrm{~cm}$ long and $12 \mathrm{~mm}$ wide core of medical grade resin that contains the electronic sensors and circuit boards. A bag is mounted on the bendable core. Pressure transducers are placed at the front, rear and inside the bag, in addition to 2 gyroscopes for orientation and angle measurements, and impedance electrodes (Fig. 5). A major novelty is the measurement of front and rear end pressures rather than radial pressure during defecation.
A

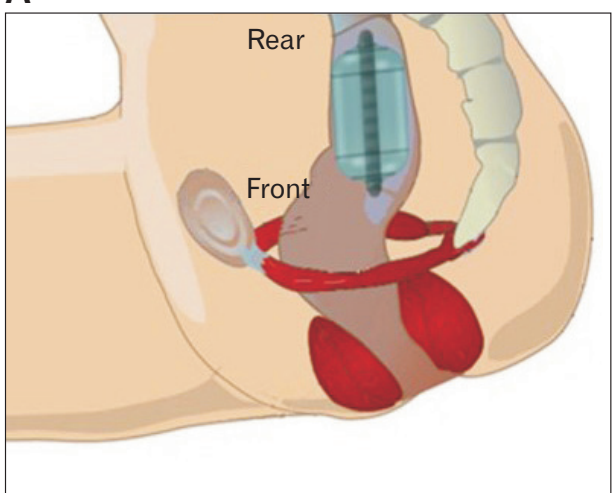

C
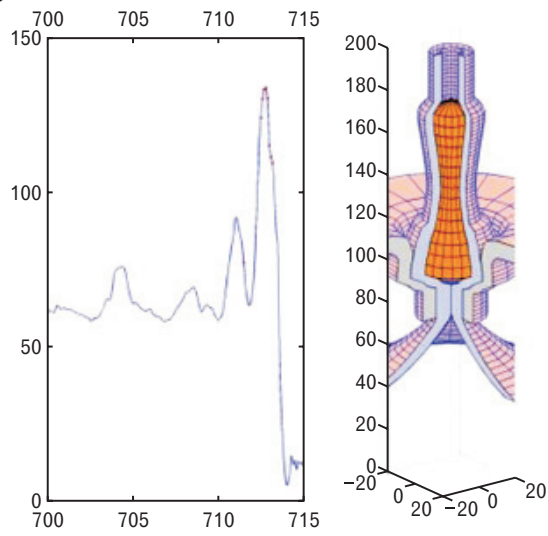

B

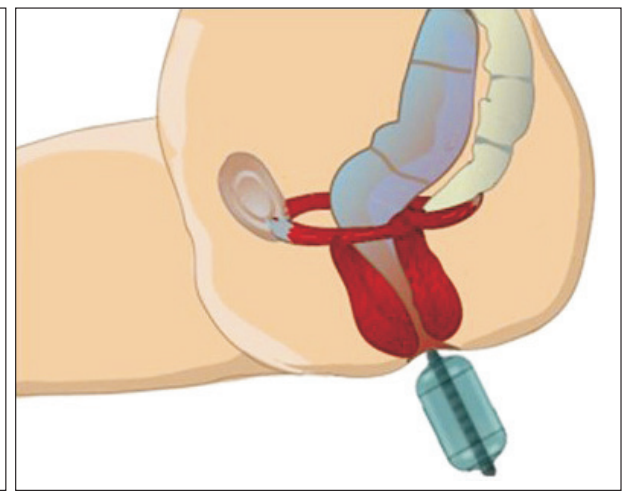

D

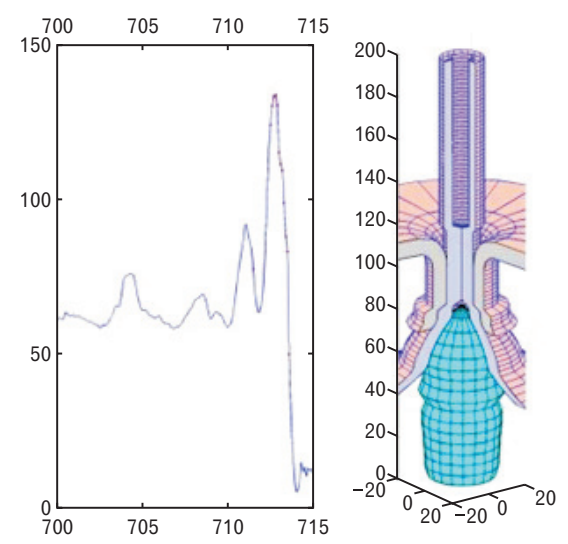

Figure 5. Schematics of the defecation of Fecobionics are shown (A and B). Simulations from human defecation experiments are shown in the bottom panels (C and D). The color of the Fecobionics bag indicate the pressure in the bag during expulsion, ie, blue is low pressure and orange is high pressure. It was possible to measure impedances, pressures, and bending of the device. The anorectal angle was measured and the shape simulated. The expulsion velocity was computed from the pressure and impedance signals. 
Current prototypes are wired and have the battery outside the anus. However, work on making the device wireless is ongoing.

\section{Fecobionics Studies}

Fecobionics is capable of measuring high-resolution pressure and impedance profiles as well as the anorectal angle during defecation. ${ }^{168}$ The impedance profiles can be simulated in different ways, ie, as semi-3D plots or video clips or as color contour plots (Fig. 5). The impedance data also allowed calculation of the expulsion velocity. In addition to the impedance plots, promising physiological data were obtained from the pressure sensors which allowed defecation to be divided into 5 distinct phases. ${ }^{168,169}$

\section{The future of Fecobionics}

Fecobionics is in its infancy and not yet Food and Drug Administration approved but nevertheless show very promising results. Successful application have been demonstrated in humans. It is the first intraluminal device measuring a variety of physiological variables during defecation. Especially, the signature from the endmounted pressure sensors demonstrating 5 phases during expulsion is novel. Since Fecobionics integrates several current tests, it potentially provides simple and inexpensive assessment of a range of defecation biomarkers that will be important in research and clinical practice. Fecobionics holds potential to differentiate patient groups and provide insight into mechanisms of anorectal disorders. Technology-related issues yet to address are making it wireless and improve position determination for identifying the trajectory. Despite the fact that no other device can provide similar recordings, it must be evaluated how Fecobionics compares with other anorectal function tests. Currently it seems that the expulsion time is comparable to that recorded with the balloon expulsion test and the bending angle corresponds to anorectal angles reported in the literature. Hence, Fecobionics data are consistent with existing tests. It is anticipated that the device can replace the balloon expulsion test and HRM but future comparative studies are needed. The clinical future of Fecobionics ultimately depends on its ability to impact on treatment of anorectal disorders. Potential clinical applications are diagnosis and biofeedback training for fecal incontinence and dyssynergic defecation.

\section{Some Bioengineering Thoughts on Impedance Planimetric Data}

The inaccessibility of visceral organs and the unavailability of tissues in many patients with motor diseases, make the modern investigator turn to the methods of mathematical modeling or numerical simulation to examine the physical processes that operate in GI sensory-motor function. However, modeling and simulation require valid data that can only be obtained from real tissues and experiments. The advances that are mentioned in this review can do much to alter our management of sensory-motor dysfunction in the GI tract in the future. This paper has outlined unique similarities between cardiac and GI muscle behavior assessed by impedance planimetry. They include especially the method that combines distension of an intraluminal bag with the depiction of the lengthtension and preload-afterload relationships in vivo, the advances in medical imaging and 3D-modeling, and the development of new ways to combine data on the properties of tissues and fluid flow. If we model the data with some simple assumptions, we can predict flow through the luminal region. New technology can advance our knowledge if it is properly applied. This will require, however, a general appreciation for mechanosensory models and simulation.

Publications on impedance planimetry, the multimodal technology, FLIP and Fecobionics demonstrate how profiling and modeling will have a role in future studies in the diagnosis and monitoring and treatment of GI diseases. This in turn will provide better models for the Human Physiome project (http://physiomeproject.org/). ${ }^{170}$ Recent initiatives such as the GIOME ${ }^{171}$ and Esophagiome projects ${ }^{172}$ will in time lead to smarter, more precise and tailored medicine and treatments. Models based on impedance planimetric data fits well here.

\section{Conclusion and Perspectives}

Impedance planimetry is a validated distension technology that has given rise to advanced muscle analysis as well as 3 applied technologies. Once a good understanding of the principles of impedance planimetry and its uses in the hollow organs is gained, the researcher can become creative about its applications and their uses. An overview of them as described here may help gain a deeper understanding of the principles involved and inspire the researcher to seek further potential applications within their own area of expertise or interest. Future aspects are described above for each of the applied technologies. Although significant progress has been made in our understanding of GI function such as sphincter dynamics and central processing of GI pain, many questions remain unresolved. For example, our understanding of the differences in EGJ geometry and in the central processing of visceral pain remains nascent. Further application of advances made in other disciplines, such as cardiology, neuroimaging, simulation and modeling, may 
be combined with impedance planimetry that may lead to many of these knowledge gaps being addressed and allow the development of routinely clinically applicable techniques that may facilitate individualization of therapy in the future.

\section{Financial support: None.}

Conflicts of interest: Hans Gregersen discloses a royalty and milestone-based agreement with Medtronic on the FLIP technology.

\section{References}

1. Farmer AD, Franchina M, Gregersen H, Penagini R, Shaker A, Soffer E. Provocative testing of the esophagus and its future. Ann N Y Acad Sci 2016;1380:33-47.

2. Krarup AL, Simrén M, Funch-Jensen P, et al. The esophageal multimodal pain model: normal values and degree of sensitization in healthy young male volunteers. Dig Dis Sci 2011;56:1967-1975.

3. Sifrim D, Blondeau K. New techniques to evaluate esophageal function. Dig Dis 2006;24:243-251.

4. Drewes AM, Reddy H, Pedersen J, Funch-Jensen, Gregersen H, Arendt-Nielsen L. Multimodal pain stimulations in patients with grade B oesophagitis. Gut 2006;55:926-932.

5. Christensen J. Origin of sensation in the esophagus. Am J Physiol 1984;246(3 Pt 1):G221-G225.

6. Gregersen H, Christensen J. Clinical mechanics in the gut: an introduction. Sharjah: Bentham Science Publishers 2016.

7. Feldman M, Friedman L, Brandt L. Sleisenger \& Fordtran's gastrointestinal and liver disease: pathophysiology, diagnosis, management. 8th edition. Readfield: Saunders 2006.

8. Gregersen H. Biomechanics of the gastrointestinal tract. London: Springer Verlag 2002.

9. McMahon BP, Rao SS, Gregersen H, et al. Distensibility testing of the esophagus. Ann N Y Acad Sci 2011;1232:331-340.

10. Lottrup C, Gregersen H, Liao D, et al. Functional lumen imaging of the gastrointestinal tract. J Gastroenterol 2015;50:1005-1016.

11. Drewes AM, Gregersen H. Multimodal pain stimulation of the gastrointestinal tract. World J Gastroenterol 2006;12:2477-2486.

12. Gregersen H, Drewes AM. Novel multimodal evaluation technology for symptom characterization in GI functional diseases and pharmacological testing of drugs. J Pharmacy Pharmacol 2014;2:231-242.

13. Drewes AM, Gregersen H, Arendt-Nielsen L. Experimental pain in gastroenterology: a reappraisal of human studies. Scand J Gastroenterol 2003;38:1115-1130.

14. Hjelland IE, Hausken T, Svebak S, Olafsson S, Berstad A. Vagal tone and meal-induced abdominal symptoms in healthy subjects. Digestion 2002;65:172-176.

15. Distrutti E, Azpiroz F, Soldevilla A, Malagelada JR. Gastric wall tension determines perception of gastric distention. Gastroenterology 1999;116:1035-1042.

16. Camilleri M. Testing the sensitivity hypothesis in practice: tools and methods, assumptions and piffalls. Gut 2002;51(suppl 1):i34-i40.

17. van der Schaar PJ, Lamers CB, Masclee AA. The role of the barostat in human research and clinical practice. Scand J Gastroenterol Suppl 1999;230:52-63.

18. Whitehead WE, Delvaux M. Standardization of barostat procedures for testing smooth muscle tone and sensory thresholds in the gastrointestinal tract. The Working Team of Glaxo-Wellcome Research. UK. Dig Dis Sci 1997;42:223-241.

19. Gregersen H. Standardization of barostat procedures. Dig Dis Sci 1998;43:1416-1420.

20. Gregersen H, Christensen J. Gastrointestinal tone. Neurogastroenterol Mot 2000;12:501-508.

21. Gregersen H, Kassab G. Biomechanics of the gastrointestinal tract. Neurogastroenterol Motil 1996;8:277-297.

22. Harris JH, Therkelsen EE, Zinner JR. Electrical measurement of ureteral flow. In: Boyarsky S, Tanagho EA, Gottschalk CW, Zimskind PD, eds. Urodynamics. London: Academic Press 2014:465-472.

23. Mortensen S, Djurhuus JC, Rask-Andersen H. A system for measurements of micturition urethral cross-sectional areas and pressures. Med Biol Eng Comput 1983;21:482-488.

24. Lose G, Colstrup H, Saksager K, Kristensen JK. New probe for measurement of related values of cross-sectional area and pressure in a biological tube. Med Biol Eng Comput 1986;24:488-492.

25. Mohrman D, Heller LJ. Cardiovascular Physiology. New York: McGraw-Hill Companies, Inc 2006.

26. Gregersen H, Stødkilde-Jørgensen H, Djurhuus JC, Mortensen SO. The four-electrode impedance technique: a method for investigation of compliance in luminal organs. Clin Phys Physiol Meas 1988;9(suppl A):61-64.

27. Gregersen H, Djurhuus JC. Impedance planimetry: a new approach to biomechanical intestinal wall properties. Dig Dis 1991;9:332-340.

28. Pandolfino JE, Bulsiewicz WJ. Evaluation of esophageal motor disorders in the era of high-resolution manometry and intraluminal impedance. Curr Gastroenterol Rep 2009;11:182-189.

29. Gregersen H, Andersen MB. Impedance measuring system for quantification of cross-sectional area in the gastrointestinal tract. Med Biol Eng Comput 1991;29:108-110.

30. Dall FH, Jørgensen CS, Djurhuus JC, Gregersen H. Biomechanical wall properties of the porcine rectum: a study using impedance planimetry. Dig Dis 1991;9:347-353.

31. Gregersen H, Jørgensen CS, Dall FH, Jensen SL. Characteristics of spontaneous and evoked motility in the isolated perfused porcine duodenum. J Appl Physiol 1992;73:9-19.

32. Gregersen, H, Jensen LS, Djurhuus JC. Changes in oesophageal wall biomechanics after portal vein banding and variceal sclerotherapy measured by a new technique. An experimental study in rabbits. Gut 1988;29:1699-1704.

33. Gregersen H, Knudsen L, Eika B, Nerstrøm LS, Rasmussen L, Jensen LS. A time-dependent study of passive esophageal wall properties 
and collagen content in rabbits with esophageal varices. Dig Dis Sci 1991;36:1050-1056.

34. Gregersen H, Giversen IM, Rasmussen LM, Tøttrup A. Biomechanical wall properties and collagen content in the partially obstructed opossum esophagus. Gastroenterology 1992;103:1547-1551.

35. Gregersen H, Barlow J, Thompson D. Development of a computercontrolled tensiometer for real-time measurements of tension in tubular organs. Neurogastroenterol Motil 1999;11:109-118.

36. Barlow JD, Gregersen H, Thompson DG. Identification of biomechanical factors associated with the perception of distension in the human esophagus. Am J Physiol Gastrointest liver Physiol 2002;282:G683G689.

37. Gao C, Petersen P, Liu W, Arendt-Nielsen L, Drewes AM, Gregersen H. Sensory-motor responses to volume-controlled duodenal distension. Neurogastroenterol Motil 2002;14:365-374.

38. Gregersen H, Kraglund K, Djurhuus JC. Variations in duodenal crosssectional area during the interdigestive migrating motility complex. Am J Physiol 1990;259:G26-G31.

39. Gregersen H, Orvar K, Christensen J. Biomechanical properties of duodenal wall and duodenal tone during phase I and phase II of the MMC. Am J Physiol 1992;263(5 Pt 1):G795-G801.

40. Rao SS, Hayek B, Mudipalli R, Gregersen H. Does esophageal function vary at the striated and smooth muscle segments in functional chest pain? Am J Gastroenterol 2002;97:2201-2207.

41. Rao SS, Hayek B, Summers RW. Functional chest pain of esophageal origin: hyperalgesia or motor dysfunction. Am J Gastroenterol 2001;96:2584-2589.

42. Gregersen H, Sørensen S, Sørensen SM, Rittig S, Andersen AJ. Measurement of anal cross-sectional area and pressure during anal distension in healthy volunteers. Digestion 1991;48:61-69.

43. Drewes AM, Pedersen J, Liu W, Arendt-Nielsen L, Gregersen H. Controlled mechanical distension of the human oesophagus: sensory and biomechanical findings. Scand J Gastroenterol 2003;38:27-35.

44. Drewes AM, Schipper KP, Dimcevski G, et al. Multi-modal induction and assessment of allodynia and hyperalgesia in the human oesophagus. Eur J Pain 2003;7:539-549.

45. Drewes AM, Pedersen J, Reddy H, et al. Central sensitization in patients with non-cardiac chest pain: clinical experimental study. Scand J Gastroenterol 2006;41:640-649.

46. Drewes AM, Reddy H, Pedersen J, Funch-Jensen P, Gregersen H, Arendt-Nielsen L. Multimodal pain stimulations in patients with grade B oesophagitis. Gut 2006;5 5:926-932.

47. Drewes AM, Reddy H, Staahl C, et al. Statistical modeling of the response characteristics of mechanosensitive stimuli in the human esophagus. Journal of Pain 2005;6:455-462.

48. Drewes AM, Reddy H, Staahl C, et al. Sensory-motor responses to mechanical stimulation of the esophagus after sensitization with acid. World J Gastroenterol 2005;11:4367-4374.

49. Drewes AM, Schipper KP, Dimcevski G, et al. Multimodal assessment of pain in the esophagus: a new experimental model 2. Am J Physiol 2002;283:G95-G103.

50. Pedersen J, Reddy H, Funch-Jensen P, Arendt-Nielsen L, Gregersen H,
Drewes AM. Cold and heat pain assessment of the human oesophagus after experimental sensitisation with acid. Pain 2004;110:393-399.

51. Pedersen J, Reddy H, Funch-Jensen P, Arendt-Nielsen L, Gregersen H, Drewes AM. Differences between male and female responses to painful thermal and mechanical stimulation of the human esophagus. Dig Dis Sci 2004;49:1065-1074.

52. Reddy H, Arendt-Nielsen L, Staahl C, et al. Gender differences in pain and biomechanical responses after acid sensitization of the human esophagus. Dig Dis Sci 2005;50:2050-2058.

53. Reddy H, Staahl C, Arendt-Nielsen L, Gregersen H, Drewes AM, Funch-Jensen P. Sensory and biomechanical properties of the oesophagus in non-erosive reflux disease. Scand J Gastroenterol 2007;42:432440.

54. Pedersen J, Gao C, Egekvist H, et al. Pain and biomechanical responses to distension of the duodenum in patients with systemic sclerosis. Gastroenterology 2003;124:1230-1239.

55. Rao SS, Gregersen H, Hayek B, Summers RW, Christensen J. Unexplained chest pain: the hypersensitive, hyperreactive, and poorly compliant esophagus. Ann Intern Med 1996;124:950-958.

56. Gregersen H, Villadsen GE, Liao D. Mechanical characteristics of distension-evoked peristaltic contractions in the esophagus of systemic sclerosis patients. Dig Dis Sci 2011;56:3559-3568.

57. Liao D, Villadsen GE, Gregersen H. Distension-evoked motility analysis in human esophagus. Neurogastroenterol Motil 2013;25:407-412, e296-e297.

58. Villadsen GE, Storkholm J, Zachariae H, Hendel L, Bendtsen F, Gregersen $\mathrm{H}$. Oesophageal pressure-cross-sectional area distributions and secondary peristalsis in relation to subclassification of systemic sclerosis. Neurogastroenterol Motil 2001;13:199-210.

59. Drewes AM, Petersen P, Rossel P, Gao C, Hansen JB, ArendtNielsen L. Sensitivity and distensibility of the rectum and sigmoid colon in patients with irritable bowel syndrome. Scand J Gastroenterol 2001;36:827-832.

60. Drewes AM, Frøkjær JB, Larsen E, Reddy H, Arendt-Nielsen L, Gregersen H. Pain and mechanical properties of the rectum in patients with active ulcerative colitis. Inflam Bowel Dis 2006;12:294-303.

61. Krogh K, Mosdal C, Gregersen H, Laurberg S. Rectal wall properties in patients with acute and chronic spinal cord lesions. Dis Colon Rectum 2002;45:641-649.

62. Pedersen J, Drewes AM, Gregersen H. New analysis for the study of the muscle function in the human oesophagus. Neurogastroenterol Motil 2005; 17:767-772.

63. Gregersen H, Liao D. New perspectives of studying gastrointestinal muscle function. World J Gastroenterol 2006;12:2864-2869.

64. Gregersen H, Pedersen J, Drewes AM. Deterioration of muscle function in the human esophagus with age. Dig Dis Sci 2008;53:3065-3070.

65. McMahon BP, Frøkjær JB, Kunwald P, et al. The functional lumen imaging probe (FLIP) for evaluation of the esophagogastric junction. Am J Physiol Gastrointest Liver Physiol 2007;292:G377-G384.

66. Liao D, Krarup AL, Lundager FH, Drewes AM, Gregersen H. Quantitative differences between primary and secondary peristaltic contractions of the esophagus. Dig Dis Sci 2014;59:18101-18106. 
67. Wu PI, Szczesniak MM, Craig PI, et al. Novel intra-procedural distensibility measurement accurately predicts immediate outcome of pneumatic dilatation for idiopathic achalasia. Am J Gastroenterol 2018;113:205-2012.

68. Carlson DA, Lin Z, Kahrilas PJ, et al. The functional lumen imaging probe detects esophageal contractility not observed with manometry in patients with achalasia. Gastroenterology 2015;149:1742-1751.

69. McMahon BP, Odie KD, Moloney KW, Gregersen H. Computation of flow through the oesophagogastric junction. World J Gastroenterol 2007;13:1360-1364.

70. Liao D, Villadsen GE, Gregersen H. Distension-evoked motility analysis in human esophagus. Neurogastroenterol Motil 2013;25:407-412, e296-e297.

71. Emery JL, Omens JH, McCulloch AD. Biaxial mechanics of the passively overstretched left ventricle. Am J Physiol 1997;272(5 Pt 2):H2299-H2305.

72. Emery JL, Omens JH, McCulloch AD. Strain softening in rat left ventricular myocardium. J Biomech Eng 1997;119:6-12.

73. Arendt-Nielsen L, Laursen RJ, Drewes AM. Referred pain as an indicator for neural plasticity. Prog Brain Res 2000;129:343-356.

74. Mayer EA, Munakata J, Mertz H, Lembo T, Bernstein CN. Visceral hyperalgesia and irritable bowel syndrome. In: Gebhart GF, ed. Visceral pain, progress in pain research and management. Seattle: IASP Press 1995:429-468.

75. Yaksh TL. Spinal systems and pain processing: development of novel analgesic drugs with mechanistically defined methods. Trends Pharmacol Sci 1999;20:329-337.

76. Olesen AE, Andresen T, Staahl C, Drewes AM. Human experimental pain models for assessing the therapeutic efficacy of analgesic drugs. Pharmacol Rev 2012;64:722-779.

77. Gebhart GF, Meller ST, Euchner-Wamser I, Sengupta JN. Modelling visceral pain. In: Vecchiet L, Albe-Fessard D, Lindblom U, Giamberardino MA, eds. New trends in referred pain and hyperalgesia. Amsterdam: Elsevier 1993:129-148.

78. Curatolo M, Petersen-Felix S, Arendt-Nielsen L. Sensory assessment of regional analgesia in humans: a review of methods and applications. Anesthesiology 2000;93:1517-1530.

79. Mehta AJ, De Caestecker JS, Camm AJ, Northfield TC. Sensitization to painful distention and abnormal sensory perception in the esophagus. Gastroenterology 1995;108:311-319.

80. DeVault KR. Acid infusion does not affect intraesophageal balloon distention-induced sensory and pain thresholds. Am J Gastroenterol 1997;92:947-949.

81. Fass R, Naliboff B, Higa L, et al. Differential effect of long-term esophageal acid exposure on mechanosensitivity and chemosensitivity in humans 1. Gastroenterology 1998;115:1363-1373.

82. Hu WH, Martin CJ, Talley NJ. Intraesophageal acid perfusion sensitizes the esophagus to mechanical distension: a Barostat study. Am J Gastroenterol 2000;95:2189-2194.

83. Sarkar S, Aziz Q, Woolf CJ, Hobson AR, Thompson DG. Contribution of central sensitisation to the development of non-cardiac chest pain. Lancet 2000;356:1154-1159.
84. Stürup G. Visceral Pain. Copenhagen: Nytt Nordisk Forlag 1940.

85. Tack JF. Chest pain of oesophageal origin. In: Corazziari E, ed. Approach to the patient with chronic gastrointestinal disorders. Milano: Messaggi 1999:153-170.

86. Lim RK, Miller DG, Guzman F, et al. Pain and analgesia evaluated by the intraperitoneal bradykinin-evoked pain method in man. Clin Pharmacol Ther 1967;8:521-542.

87. Bernstein L, Baker LA. A clinical test for esophagitis. Gastroenterology 1958;34:760-781.

88. Richter JE. Acid perfusion (Bernstein) test. In: Castell DO, Wu WC, Ott DJ, eds. Gastroesophageal reflux disease. Pathogenesis, diagnosis and therapy. Mount Kesco: Futura Publishing Co Inc 1985:139-148.

89. Jung B, Steinbach J, Beaumont C, Mittal RK. Lack of association between esophageal acid sensitivity detected by prolonged $\mathrm{pH}$ monitoring and Bernstein testing. Am J Gastroenterol 2004;99:410-415.

90. Katz PO, Dalton CB, Richter JE, Wu WC, Castell DO. Esophageal testing in patients with non-cardiac chest pain or dysphagia. Ann Intern Med 1987;6:593-597.

91. Fass R, Achem SR. Noncardiac chest pain: epidemiology, natural course and pathogenesis. J Neurogastroenterol Motil 2011;17:110-123.

92. Hewson EG, Sinclair JW, Dalton CB, Wu WC, Castell DO, Richter JE. Acid perfusion test: does it have a role in the assessment of non cardiac chest pain? Gut 1989;30:305-310.

93. Sharma A, Paine P, Rhodes S, Warbuton F, Chua YC, Aziz Q. The autonomic response to human esophageal acidification and the development of hyperalgesia. Neurogastroenterol Motil 2012;24:e285-e293.

94. Tougas G, Spaziani R, Hollerbach S, et al. Cardiac autonomic function and oesophageal acid sensitivity in patients with non-cardiac chest pain. Gut 2001;49:706-712.

95. Forcelini CM, Tomiozzo JC Jr, Farré R, et al. Effect of nortriptyline on brain responses to painful esophageal acid infusion in patients with nonerosive reflux disease. Neurogastroenterol Motil 2014;26:187-195.

96. Reeves JW, Al-Zinaty M, Woodland P, Sifrim D, Aziz Q, Birch MJ. Sensiprobe--a miniature thermal device incorporating Peltier technology as a diagnostic tool for studying human oesophageal sensitivity. Physiol Meas 2014;35:1265-1277.

97. Maule WF, Baer PE, Fuhrer MJ. A device for studying the psychophysiologic effects of thermal stimulation of the human esophagus. Psychophysiology 1975;12:212-216.

98. Accarino AM, Azpiroz F, Malagelada JR. Symptomatic responses to stimulation of sensory pathways in the jejunum. Am J Physiol 1992;263(5 Pt 1):G673-G677.

99. Loening-Baucke V, Read NW, Yamada T. Further evaluation of the afferent nervous pathways from the rectum. Am J Physiol 1992;262:G927-G933.

100. Ohman U. Studies on small intestinal obstruction. III. Circulatory effects of artificial small bowel distension. Acta Chir Scand 1975;141:536544.

101. Gregersen H, Christensen J. Mechanically restricted regional blood flow might explain gastrointestinal pain. Nat Clin Pract Gastroenterol Hepatol 2005;2:378-379.

102. Staahl C, Drewes AM. Experimental human pain models: a review of 
standardised methods for preclinical testing of analgesics. Basic Clin Pharmacol Toxicol 2004;95:97-111.

103. Brock C, Brokjaer A, Drewes AM, et al. Neurophysiology of the esophagus. Ann N Y Acad Sci 2014;1325:57-68.

104. Gao C, Arendt-Nielsen L, Liu W, Petersen P, Drewes AM, Gregersen $\mathrm{H}$. Sensory and biomechanical responses to ramp-controlled distension of the human duodenum. Am J Physiol 2003;284:G461-G471.

105. Gao C, Pedersen J, Arendt-Nielsen L, Drewes AM, Gregersen H. Age related variation in mechanical and sensory function of the human duodenum. J Appl Res 2004;4:99-100.

106. Staahl C, Reddy H, Andersen SD, Arendt-Nielsen L, Drewes AM. Multi-modal and tissue-differentiated experimental pain assessment: reproducibility of a new concept for assessment of analgesics. Basic Clin Pharmacol Toxicol 2006;98:201-211.

107. Frøkjaer JB, Liao D, Bergmann A, et al. Three-dimensional biomechanical properties of the human rectum evaluated with magnetic resonance imaging. Neurogastroenterol Motil 2005;17:531-540.

108. Brock C, Nissen TD, Gravesen FH, et al. Multimodal sensory testing of the rectum and rectosigmoid: development and reproducibility of a new method. Neurogastroenterol Motil 2008;20:908-918.

109. Krarup AL, Olesen SS, Funch-Jensen P, Gregersen H, Drewes AM. Proximal and distal esophageal sensitivity is decreased in patients with Barrett's esophagus. World J Gastroenterol 2011;17:514-521.

110. Lottrup C, Krarup AL, Gregersen H, et. al. Barrett's esophagus patients show hypersensitivity to acid but hyposensitivity to other esophageal stimuli [abstract]. OESO conference Proceedings 2015.

111. Richter JE, Barish CF, Castell DO. Abnormal sensory perception in patients with esophageal chest pain. Gastroenterology 1986;91:845-852.

112. Smout AJ, Devore MS, Dalton CB, Castell DO. Cerebral potentialsevoked by esophageal distension in patients with noncardiac chest pain. Gut 1992;33:298-302.

113. Barish CF, Castell DO, Richter JE. Graded esophageal balloon distention. A new provocative est for noncardiac chest pain. Dig Dis Sci 1986;31:1292-1298.

114. Cannon RO 3rd, Benjamin SB. Chest pain as a consequence of abnormal visceral nociception. Dig Dis Sci 1993;38:193-196.

115. Hollerbach S, Bulat R, May A, et al. Abnormal cerebral processing of oesophageal stimuli in patients with noncardiac chest pain (NCCP). Neurogastroenterol Motil 2000;12:555-565.

116. Hoff DA, Krarup AL, Lelic D, et al. Central response to painful electrical esophageal stimulation in well-defined patients suffering from functional chest pain. Neurogastroenterol Motil 2013;25:e718-e727.

117. Brock C, Søfteland E, Gunterberg V, et al. Diabetic autonomic neuropathy affects symptom generation and brain-gut axis. Diabetes Care 2013;36:3698-3705.

118. Frøkjær JB, Andersen SD, Eskjaer N, et al. Gut sensations in diabetic autonomic neuropathy. Pain 2007;131:320-329.

119. Staahl C, Christrup LL, Andersen SD, Arendt-Nielsen L, Drewes AM. A comparative study of oxycodone and morphine in a multimodal, tissue-differentiated experimental pain model. Pain 2006;123:2836.

120. Lelic D, Olesen AE, Gregersen H, Dahan A, Kolesnikov Y, Drewes
AM. Morphine modifies the cingulate-operculum network underlying painful rectal evoked potentials. Neuropharmacology 2014;77:422-427.

121. Mayer EA, Naliboff BD, Craig AD. Neuroimaging of the brain-gut axis: from basic understanding to treatment of functional GI disorders. Gastroenterology 2006;131:1925-1942.

122. Frøkjaer JB, Olesen SS, Graversen C, Andresen T, Lelic D, Drewes AM. Neuroimaging of the human visceral pain system—a methodological review. Scand J Pain 2011;2:95-104.

123. Liu J, Parashar VK, Mittal RK. Asymmetry of lower esophageal sphincter pressure: is it related to the muscle thickness or its shape? Am J Physiol 1997;272:G1509-G1517.

124. Dent J. New technique for continuous sphincter pressure measurement. Gastroenterology 1976;71:263-267.

125. Nicodème F, Lin Z, Pandolfino JE, Kahrilas PJ. Esophagogastric junction pressure morphology: comparison between a station pull-through and real-time 3D-HRM representation. Neurogastroenterol Motil 2013;25:e591-e598.

126. Gotley DC, Barham CP, Miller R, Arnold R, Alderson D. The sphinctometer: a new device for measurement of lower oesophageal sphincter function. Br J Surg 1991;78:933-935.

127. McMahon BP, Drewes AM, Gregersen H. Functional oesophagogastric junction imaging. World J Gastroenterol 2006;12:2818-2824.

128. McMahon BP, Jobe BA, Pandolfino JE, Gregersen H. Do we really understand the role of the oesophagogastric junction in disease? World J Gastroenterol 2009;15:144-150.

129. Patel RS, Rao SS. Biomechanical and sensory parameters of the human esophagus at four levels. Am J Physiol 1998;275(2 Pt 1):G187-G191.

130. Shaker R, Bardan E, Gu C, et al. Effect of lower esophageal sphincter tone and crural diaphragm contraction on distensibility of the gastroesophageal junction in humans. Am J Physiol 2004;287:G815-G821.

131. Pandolfino JE, Shi G, Curry J, Joehl RJ, Brasseur JG, Kahrilas PJ. Esophagogastric junction distensibility: a factor contributing to sphincter incompetence. Am J Physiol Gastrointest Liver Physiol 2002;282:G1052-G1058.

132. Liu J, Takeda T, Dogan I, Bhargava V, Mittal RK. Oesophago-gastric junction opening function: assessment using ultrasound imaging and the effects of atropine. Neurogastroenterol Motil 2006;18:376-384.

133. Andersen IS, Gregersen H, Buntzen S, Djurhuus JC, Laurberg S. New probe for the measurement of dynamic changes in the rectum. Neurogastroenterol Motil 2004;16:99-105.

134. McMahon BP, Frøkjaer JB, Drewes AM, Gregersen H. A new measurement of oesophago-gastric junction competence. Neurogastroenterol Motil 2004;16:543-546.

135. McMahon BP, Frøkjaer JB, Liao D, Kunwald P, Drewes AM, Gregersen $\mathrm{H}$. A new technique for evaluating sphincter function in visceral organs: application of the functional lumen imaging probe (FLIP) for the evaluation of the oesophago-gastric junction. Physiol Meas 2005;26:823-836.

136. Clouse RE, Staiano A. Topography of the esophageal peristaltic pressure wave. Am J Physiol 1991;261(4 Pt 1):G677-G684.

137. Clouse RE, Prakash C. Topographic esophageal manometry: an emerging clinical and investigative approach. Dig Dis 2000;18:64-74. 
138. Kwiatek M, Pandolfino JE, Hirano I, Kahrilas PJ. Esophagogastric junction distensibility assessed with an endoscopic functional luminal imaging probe (EndoFLIP). Gastrointest Endosc 2010;72:272-278.

139. Luft F, Fynne L, Gregersen H, et al. Functional luminal imaging probe: a new technique for dynamic evaluation of mechanical properties of the anal canal. Tech. Coloproctol 2012;16:451-457.

140. Gregersen H. Analysis of functional luminal imaging probe data. Clin Gastroenterol Hepatol 2017;15:1313-1314.

141. Gregersen H. Reply. Clin Gastroenterol Hepatol 2017;15:1978-1979.

142. Sørensen G, Liao D, Lundby L, et al. Distensibility of the anal canal in patients with idiopathic fecal incontinence: a study with the functional lumen imaging probe. Neurogastroenterol Motil 2014;26:255-263.

143. Regan J, Walshe M, Rommel N, McMahon BP. A new evaluation of the upper esophageal sphincter using the functional lumen imaging probe: a preliminary report. Dis Esophagus 2013;26:117-123.

144. Regan J, Walshe M, Rommel N, Tack J, McMahon B. New measures of upper esophageal sphincter distensibility and opening patterns during swallowing in healthy subjects using EndoFLIP ${ }^{\circledR}$. Neurogastroenterol Motil 2013;25:e25-e34.

145. Regan J, Walshe M, Timon C, McMahon BP. Endoflip ${ }^{\circledR}$ evaluation of pharyngo-oesophageal segment tone and swallowing in a clinical population: a total laryngectomy case series. Clin Otolaryngol 2015;40:121129.

146. Carlson DA, Hirano I. Application of the functional lumen imaging probe to esophageal disorders. Curr Treat Options Gastroenterol 2017;15:10-25.

147. Chen JW, Pandolfino JE, Lin Z, et al. Severity of endoscopically identified esophageal rings correlates with reduced esophageal distensibility in eosinophilic esophagitis. Endoscopy 2016;48:794-801.

148. Kwiatek MA, Kahrilas K, Soper NJ, et al. Esophagogastric junction distensibility after fundoplication assessed with a novel functional luminal imaging probe. J Gastrointest Surg 2010;14:268-276.

149. Ilczyszyn A, Botha AJ. Feasibility of esophagogastric junction distensibility measurement during Nissen fundoplication. Dis Esophagus 2014;27:637-644.

150. Hoppo T, McMahon BP, Witteman BP, et al. Functional lumen imaging probe to assess geometric changes in the esophagogastric junction following endolumenal fundoplication. J Gastrointest Surg 2011;15:1112-1120.

151. Lottrup C, McMahon BP, Ejstrud P, Ostapiuk MA, Funch-Jensen P, Drewes AM. Esophago-gastric junction distensibility in hiatus hernia. Dis Esophagus 2016;29:463-471.

152. Rohof W, Hirsch D, Kessing BF, Boeckxstaens GE. Efficacy of treatment for patients with achalasia depends on the distensibility of the esophagogastric junction. Gastroenterology 2012;143:328-335.

153. Teitelbaum EN, Boris L, Arafat FO, et al. Comparison of esophagogastric junction distensibility changes during POEM and Heller myotomy using intraoperative FLIP. Surg Endosc 2013;27:4547-4555.

154. Teitelbaum EN, Soper NJ, Pandolfino JE, et al. Esophagogastric junction distensibility measurements during Heller myotomy and POEM for achalasia predict postoperative symptomatic outcomes. Surg Endosc 2015;29:522-528.
155. Familiari P, Gigante G, Marchese M, et al. EndoFLIP system for the intraoperative evaluation of peroral endoscopic myotomy. United European Gastroenterol J 2014;2:77-83.

156. Teitelbaum EN, Soper NJ, Pandolfino JE, et al. An extended proximal esophageal myotomy is necessary to normalize EGJ distensibility during Heller myotomy for achalasia, but not POEM. Surg Endosc 2014;28:2840-2847.

157. Perretta S, Dallemagne B, McMahon B, D’Agostino J, Marescaux J. Video. Improving functional esophageal surgery with a "smart" bougie. Endoflip Surg Endosc 2011;25:3109.

158. Tucker E, Sweis R, Anggiansah A, et al. Measurement of esophagogastric junction cross-sectional area and distensibility by an endolumenal functional lumen imaging probe for the diagnosis of gastro-esophageal reflux disease. Neurogastroenterol Motil 2013;25:904-910.

159. Fynne L, Liao D, Aksglaede K, et al. Esophagogastric junction in systemic sclerosis: A study with the functional lumen imaging probe. Neurogastroenterol Motil Published Online First: 3 May 2017. doi: 10.1111/nmo.13073.

160. Malik Z, Sankineni A, Parkman HP. Assessing pyloric sphincter pathophysiology using EndoFLIP in patients with gastroparesis. Neurogastroenterol Motil 2015;27:524-531.

161. Alqudah MM, Gregersen H, Drewes AM, McMahon, BP. Evaluation of anal sphincter resistance and distensibility in healthy controls using EndoFLIPC. Neurogastroenterol Motil 2012;24:e591-e599.

162. Fynne L, Luft F, Gregersen H, et al. Distensibility of the anal canal in patients with systemic sclerosis: a study with the functional lumen imaging probe. Colorectal Dis 2013;15:e40-e47.

163. Yamada T, Alpers TH, Kalloo AN, et al. Textbook of gastroenterology. New York: Blackwell Publishing Ltd 2009:1717-1744.

164. Rao SS, Bharacha AE, Chiarioni G, et al. Functional anorectal disorders. Gastroenterology 2016;150:1430-1442, e4.

165. Bharucha AE, Wald A, Enck P, Rao S. Functional anorectal disorders. Gastroenterology 2006;130:1510-1518.

166. Palit S, Thin N, Knowles CH, Lunniss PJ, Bharucha AE, Scott SM. Diagnostic disagreement between tests of evacuatory function: a prospective study of 100 constipated patients. Neurogastroenterol Motil 2016;28:1589-1598.

167. Pelsang RE, Rao SS, Welcher K. FECOM: a new artificial stool for evaluating defecation. Am J Gastroenterol 1999;94:183-186.

168. Gregersen H, Krogh K, Liao D. Fecobionics: integrating anorectal function measurements. Clin Gastroenterol Hepatol Published Online First: 6 Oct 2017. doi: 10.1016/j.cgh.2017.09.057.

169. Gregersen H, Fecobionics: a novel bionic test of anorectal function and defecation. Gastroenterology 2017;152:S317.

170. Hunter PJ. The IUPS physiome project: a framework for computational physiology. Prog Biophys Mol Biol 2004;85:551-569.

171. Gregersen H. The Giome project. Neurogastroenterol Motil 2006;18:401-402.

172. Gregersen H, Liao D, Brasseur JG. The esophagiome: concept, status, and future perspectives. Ann N Y Acad Sci 2016;1380:6-18. 